\title{
In Retrospect: Lucifer's Hammer
}

\section{Oliver Morton recalls how the first major science fiction novel to depict an impact event conjured the thrill and the horror of natural cataclysm - and even inspired some researchers.}

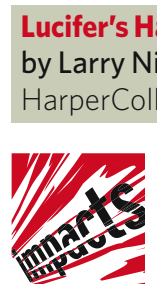

Lucifer's Hammer

by Larry Niven and Jerry Pournelle

HarperCollins: 1977. 494 pp.

Everyone remembers the surfer. When fragments of comet Hamner-Brown strike Earth a third of the way into Lucifer's Hammer, the surfer is floating on his board off Santa Monica, California. The flash in the sky and the fiery cloud on the horizon warn him what's coming. He paddles out to face his death - a tsunami that lifts him to the sky and turns him to the land. He rides the end of the world into the Los Angeles basin like a Hot Tuna Valkyrie, locomotive-fast and skyscraper-high, imagining for a moment that, despite the unbearable strain in his legs and the weight of an ocean at his back, he might still survive to tell his story: "a surfing movie with ten million in special effects!"

The surfer is remembered because he provides the novel's most enduring taste of the sublime - a simultaneous evocation of terror and wonder, immediate danger and cognitive distance, common to disasters imagined and real. As The Times columnist Matthew Parris put it, writing with disturbing honesty about the mixed horror and thrill he felt contemplating the Indian Ocean tsunami of 2004: "A minor but insuppressible part of me has almost relished - yes, relished - those huge numbers. As the newspaper headlines spoke greedily of the numbers of dead "approaching" twenty, then fifty, then eighty, then a hundred thousand, something undeniable twitched in the back of my brain ... as though some great auctioneer of calamity were taking bids from the media floor, and I was willing the bidding to carry on upwards.... When the gods themselves strike - then I believe a new depth to our fascination opens."

Published in 1977, Lucifer's Hammer was the first major science fiction novel to try to deal realistically with the planetary emergency of an impact event. It plumbs those depths of fascination on an epic scale, rewarded at the time with sales far beyond the normal expectations of the genre.

Authors Larry Niven and Jerry Pournelle originally outlined a story in which aliens, planning to invade, drop a small asteroid on the earth as a useful softening-up exercise. Their editor told them to forget the aliens and concentrate on the asteroid. They did so, making it the centre-piece of a disaster novel carefully fashioned for best-sellerdom, with a large cast and a heft that promises to take up a lot of beach time. In the process they converted the asteroid to a less predictable but more spectacular comet, with doubts about its trajectory allowing a tension-building introduction to their disaster-movie-ready cast of Angelenos.

The novel works well, still, as an airport read. (It is better than the alien-invasion novel the authors finally wrote almost a decade later, although to be fair, Footfall (Del Rey, 1985)

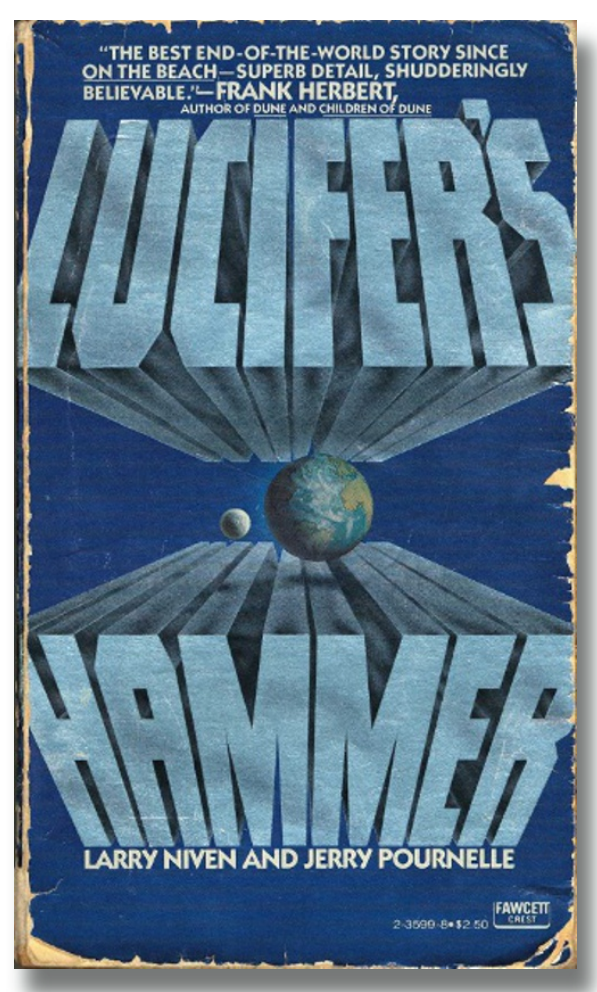

does have a magnificent space battle at its finale.) And Lucifer's Hammer is distinguished by its thorough and informed imagining of a broadly plausible cataclysm never before described. Niven and Pournelle went out of their way to make the impact and its attendant horrors - tsunamis, earthquakes, climate change and crop failure, wars for the best remaining farmland - believable at a time when remarkably little scientific attention had been paid to such things. When the book emerged, it encouraged more of that attention. "Lucifer's Hammer killed the dinosaurs," said US physicist Luis Alvarez, saluting the authors when, a few years later, they attended his lecture on the geochemical evidence he and his son had found of a massive impact at the end of the Cretaceous period.

For all that, the book isn't about the comet. It is about the enervating fragility of civilization. Pre-comet, Los Angeles is already perched on the cusp of disaster, as always; in the city's Cielo Drive, Charles Manson has already proved civilization "neither eternal nor safe". "Nothing silly about being ready for the end of civilization," opines a wise biker camping off Mulholland. There's a period pall of sweaty paranoia and doom that gives the impact an almost cleansing feel. At times, the thrill of destruction and survival seems to totter into glee at the settling of scores. Feminism does not outlast the cataclysm, and it is not much missed. Woolly-headed pinko environmentalists eat their enemies and each other, as do most of the book's black characters - a development with disturbing echoes, to say the least, of George Fitzhugh's 1857 antebellum tract Cannibals All! or, Slaves Without Masters.

The authors' main theme is that, comet or no, a civilization has the morality its machinery allows it to afford, and that saving the last nuclear power plant is worth a war if it avoids a return to serfdom and slavery. Pangs of survivor guilt and a nostalgia for lost niceties cut across the suspicion that some of the protagonists like the Hammer-scourged world a bit too much. The sacrifice of the scientist who devotes his last winter to making poison gases for the power plant's protection, rather than insulin that would save his own life, is manipulative. But it is plausibly and effectively so. And the richer crops that grow where the gas pooled and corpses fell are a powerful symbol of good from ill. It is hard not to feel a sense of uplift as, on the last page, emblems of industry and trade - electricity, an IOU and, most beautifully, an aircraft's contrail — herald returning life and dignity.

Oliver Morton is Nature's Chief News and

Features Editor. He is author of Mapping Mars and Eating the Sun.

See Editorial, page 1143. 